\title{
Is intramedullary nailing more effective than non-operative treatment in adults with displaced middle-third clavicle fractures?
}

\author{
Christopher Edward Hill
}

Received: 4 April 2013/Accepted: 6 May 2014/Published online: 31 May 2014

(C) The Author(s) 2014. This article is published with open access at Springerlink.com

\begin{abstract}
Background Clavicle fractures are common, accounting for 5-12\% of all fractures. Traditionally, displaced middle-third clavicle fractures have been managed non-operatively but the associated displacement often leads to malunion with shortening, cosmetic deformity and occasionally non-union, with clinicians looking towards alternative operative methods such as intramedullary nailing (IMN). However, such methods have their own complications. In order to ascertain the effectiveness of IMN in the management of middle-third clavicle fractures compared with non-operative treatment, analysis of recent evidence is required and this review aims to achieve that, focusing on relevant, contemporary randomised-control trials.

Materials and methods Essential search-terms identified from the research question were used to formulate a search strategy. A systematic search of multiple databases was then performed from 1966 until present and appropriate papers for appraisal identified.

Results Thirteen papers were identified, with 10 excluded using appropriate eligibility criteria. The remaining papers were then critically appraised. With regards shoulder function, all papers demonstrated an association between IMN and a significantly $(P<0.05)$ superior shoulder function score, but no consensus with regards to complication rates. However, all have identified limitations;
\end{abstract}

C. E. Hill ( $\square)$

46, Hermitage Road, Kenilworth, Warwickshire CV8 2DW, UK

e-mail: chill295@doctors.net.uk

C. E. Hill

University Hospital of Coventry and Warwickshire, Clifford

Bridge Road, Coventry CV22 5PX, UK therefore, their overall findings must be considered conservatively.

Conclusions Further, high-quality research, ideally in the form of well-designed, multi-centre RCTs is required to allow acceptable implementation of IMN of middle-third clavicle fractures into widespread practice. However, early results demonstrate that in young patients with displaced middle-third clavicle fractures, who are motivated to return to work, IMN provides superior functional results and should be considered. However, the importance of considering each patient individually as to their suitability for each management option, before coming to an informed decision with the patient rather than having a blanket approach to MTCF is essential.

Level of Evidence Level 1.

Keywords Fracture $\cdot$ Clavicle $\cdot$ Nailing $\cdot$ Pinning · Intramedullary $\cdot$ Trauma

\section{Introduction}

This review aims to use clinically based, contemporary literature to ascertain whether intramedullary nailing (IMN) is a more beneficial management technique than non-operative management in adult middle-third clavicle fractures (MTCF) with regards to shoulder function.

Clavicle fractures account for 5-12\% of all fractures, with an estimated incidence of 29-64/100,000 adult population/year [1-4]. Eighty per cent occur in the middlethird zone of the clavicle, identified as Grade 1 using the anatomical Allman classification [5] (Table 1).

Most MTCF are displaced by the deforming pull of associated muscle attachments [6-8]. Traditionally, MTCF have been managed non-operatively [9-11], however, the 
Table 1 The Allman classification of clavicle fractures

\begin{tabular}{ll}
\hline Grade 1: & Fractures of the middle-third of the clavicle \\
Grade 2: & $\begin{array}{l}\text { Fractures of the clavicle distal to the coracoclavicular } \\
\text { ligament (lateral) }\end{array}$ \\
Grade 3: & Fractures of the proximal end of the clavicle (medial)
\end{tabular}

Table 2 Internal plate fixation complications [16, 54]

\begin{tabular}{ll}
\hline Internal plate fixation complications & \\
Deep infection & Implant failure \\
Loosening & Wide surgical exposure \\
Large scar/poor cosmesis & Neurovascular problem \\
Prominence & Non-/mal-union \\
Re-fracture & Need for metalwork removal \\
\hline
\end{tabular}

associated displacement often leads to mal-union with shortening, cosmetic deformity and occasionally non-union $[1,12$, 13]. In connecting the upper limb with the thoracic cage, the clavicle is salient to shoulder mechanics and stabilising the shoulder girdle, hence fracture patients with loss of length and curvature have been reported to suffer with residual deficits in shoulder strength and endurance $[1,3,12,13]$.

These potential drawbacks demonstrate why MTCF management has become increasingly controversial, with clinicians looking towards alternative operative methods $[1,14]$. Two main operative methods exist: internal plate fixation and IMN [15]. Internal plate fixation has been shown to have a number of complications, (Table 2), leading many to explore IMN [16]:

Clavicle IMN was initially described over 50 years ago $[17,18]$. Biomechanically, the technique provides optimal fracture stabilisation and aims to preserve clavicular length, avoiding mal-union and maintaining good cosmetic and functional results, allowing faster return to daily activities and employment [19]. However, concerns regarding complication rates have raised doubts as to the best treatment method [17, 20]. Cochrane reviews have separately studied non-operative and operative treatment methods but not compared the two; therefore, given the fracture's common incidence and management choice controversy, this review is fully justified $[15,21]$.

Evidence-based medicine is defined as "the conscientious, explicit and judicious use of current best evidence in making decisions about the care of individual patients" [22]. In order to ascertain the effectiveness of IMN in the management of adult MTCF compared with non-operative treatment, analysis of recent evidence is required and this paper aims to achieve that.

The Population, Intervention, Comparator and Outcome (PICO) process [23], was used to formulate the research question: in adults with middle-third clavicle fractures, is intramedullary nailing a more beneficial management
Table 3 Literature search strategy example-medline $(\mathrm{OVID})^{\circledR}$ 1948 to date

\begin{tabular}{llrl}
\hline$\#$ & Searches & Results & $\begin{array}{l}\text { Search } \\
\text { type }\end{array}$ \\
\hline 1 & Nonoperative.mp. & 6,003 & Advanced \\
2 & Non-operative.mp. & 2,368 & Advanced \\
3 & Conservative.mp. & 64,268 & Advanced \\
4 & 1 or 2 or 3 & 71,706 & Advanced \\
5 & Exp Bone Nails/or exp Fracture Fixation, & 18,654 & Advanced \\
& Intramedullary/or intramedullary.mp. & & \\
6 & 4 and 5 & 506 & Advanced \\
7 & Clavicle.mp. or exp Clavicle/or & 6,448 & Advanced \\
& clavicular.mp. or exp Clavicular/ & & \\
8 & 6 and 7 & 47 & Advanced \\
9 & Limit 8 to English language & 29 & Advanced \\
10 & Limit 9 to humans & 28 & Advanced \\
11 & Limit 10 to last 10 years & 21 & Advanced \\
9 & Limit 11 to comparative study & 6 & Advanced \\
\hline
\end{tabular}

The search strategies for the remaining databases can be found in Appendix. Search performed 20 September, 2012

technique than non-operative treatment with regards to shoulder function? The secondary outcome of complications was also investigated.

\section{Materials and methods}

Having identified an appropriate, focussed research question, a search strategy was formulated with key concepts and keywords identified using the PICO process [23], identifying essential search-terms [24] which were exploded ensuring inclusion of relevant synonyms, alternative spellings and related terms. Individual search-terms were then combined using a Boolean technique $[25,26]$ to refine further.

Initial search keywords were broad, exploded terms to ensure full use of MeSH (Medical Subject Headings) terms for maximum sensitivity [26-28]. More specific terms and limitations were subsequently introduced and combined to refine the search [29]. Table 3 displays the full search strategy used.

The eligibility criteria selected are displayed in Table 4.

Multiple databases were used to ensure a thorough search was performed as no single database can cover all the resources within a given field [27]. These were: Medline, EMBASE and Web of Knowledge. The reference lists of all RCTs identified were hand-searched to identify further relevant articles.

Following the search, three papers were selected for critical appraisal, which is defined as the "process of systematically examining research evidence to assess its 
Table 4 Inclusion and exclusion criteria

\begin{tabular}{|c|c|c|}
\hline Criteria type & Description & Rationale for criteria \\
\hline \multirow[t]{6}{*}{ Inclusion criteria } & $\begin{array}{l}\text { Middle-third/midshaft clavicle } \\
\text { fracture }\end{array}$ & Majority site for clavicle fractures \\
\hline & Human subjects & Applicability to patients \\
\hline & IMN as only defined intervention & As per research question \\
\hline & Comparative study & $\begin{array}{l}\text { To ensure papers selected for analysis were of a suitably high level in the evidence } \\
\text { hierarchy [32] and allow comparison of intervention and comparator methods }\end{array}$ \\
\hline & In English language & $\begin{array}{l}\text { Deemed financially and temporarily inappropriate for this review for translation } \\
\text { services of non-English papers despite potentially excluding relevant papers }\end{array}$ \\
\hline & Published within last 10 years & To gain the most contemporary evidence available given scope of review \\
\hline \multirow{6}{*}{$\begin{array}{l}\text { Exclusion } \\
\text { criteria }\end{array}$} & Medial/lateral end of clavicle fracture & Rarer, uncommon type of fracture requiring different treatment considerations \\
\hline & Non-human subjects/animal studies & Applicability to patients \\
\hline & Alternative intervention, e.g. plating & As per research question \\
\hline & Non-comparative studies & $\begin{array}{l}\text { To ensure papers selected for analysis were of a suitably high level in the evidence } \\
\text { hierarchy [32] and allow comparison of intervention and comparator methods }\end{array}$ \\
\hline & Languages other than English & $\begin{array}{l}\text { Deemed financially and temporarily inappropriate for this review for translation } \\
\text { services of non-English papers despite potentially excluding relevant papers }\end{array}$ \\
\hline & Published prior to last 10 years & To gain the most contemporary evidence available given scope of review \\
\hline
\end{tabular}

validity, results and relevance, before using it to inform a decision" [31:1]. To ensure a systematic, logical and standardised approach to the appraisal, the CASP reviewer check-list was used [30].

\section{Results}

The results of the database searches are displayed in Table 3 and Appendix.

The aforementioned search criteria identified 13 papers, with 10 excluded as detailed in Table 5.

This left 3 papers for critical appraisal, presented in Table 6, hereon referred to as papers 1-3.

\section{Critical Appraisal}

\section{Paper 1}

This single-centre, prospective, controlled trial compared elastic IMN with non-operative treatment of displaced MTCF in adults aged 16-85. The paper lacked a clearlyfocussed PICO-adhering research question [23]. The study population was defined using detailed eligibility criteria, and the comparative treatment was well described, both of which demonstrate good study design. The intervention was lacking in detail and although a standardised surgical method was well described, no detail was provided regarding the operating surgeons, predisposing it to intersurgeon variability and proficiency bias [31]. However, the thorough description of the surgical method allows reproducibility of the study, making it generalisable. The study
Table 5 Excluded studies following database searches

\begin{tabular}{ll}
\hline Study & Reason for exclusion \\
\hline Houwert et al. [1] & Alternative intervention of plate fixation \\
Assobhi [56] & Alternative intervention of plate fixation \\
Duan et al. [57] & Alternative intervention of plate fixation \\
McKee [58] & Alternative intervention of plate fixation \\
Wijdicks et al. [59] & Alternative intervention of plate fixation \\
Ferran et al. [60] & Alternative intervention of plate fixation \\
Proubasta et al. [61] & $\begin{array}{l}\text { Alternative intervention of plate fixation, } \\
\text { cadaver study }\end{array}$ \\
Simon [62] & Not comparative study \\
O'Brian and Savoie [63] & Not comparative study \\
Thompson [64] & Not comparative study
\end{tabular}

controversially selects two primary outcomes: time-tounion, for which the assessment process was explained in detail; and clavicular shortening, for which the assessment method was lacking. Secondary outcomes to be assessed are stated, but no description of data collection was provided, weakening study strength.

The study compared the efficacy of an interventional treatment with a comparison treatment and therefore an RCT is the preferred study design [32]. Despite being a prospective, controlled study using a well-recognised randomisation technique, it is stated as not being a RCT, with little justification. This is an unclear statement, especially given the low level of present evidence, meaning a goldstandard RCT would be highly appropriate for this comparative-clinical question [32]. 
Table 6 Final papers identified for critical appraisal

\begin{tabular}{llc}
\hline Paper & Title & References \\
\hline Paper 1 & $\begin{array}{c}\text { Elastic stable intramedullary nailing is best } \\
\text { for mid-shaft clavicular fractures without } \\
\text { comminution: results in 60 patients }\end{array}$ & $\begin{array}{c}\text { Smekal } \\
\text { et al. [19] }\end{array}$ \\
Paper 2 & $\begin{array}{c}\text { Acute operative stabilization versus non- } \\
\text { operative management of clavicle fractures }\end{array}$ & $\begin{array}{c}\text { Judd et al. } \\
\text { [65] }\end{array}$ \\
Paper 3 & $\begin{array}{c}\text { Elastic stable intramedullary nailing versus } \\
\text { non-operative treatment of displaced } \\
\text { clavicular fractures-a randomized, }\end{array}$ & $\begin{array}{c}\text { Smekal } \\
\text { et al. [66] }\end{array}$ \\
& controlled, clinical trial & \\
\hline
\end{tabular}

The allocation-concealment process was briefly described as a single-block random assignment. This is a recognised, standardised method of true randomisation, which is a positive. However, no further information was provided regarding who performed the randomisation, use of blinding, sequence generation or treatment allocation. There was no mention of computer-assisted randomisation, and no audit trail to ensure reliability of the process. This lack of detail impacts negatively on the study, especially given that the authors later state it was not a RCT, raising suspicion regarding the validity of the randomisation process. Using a variable-block method is less predictable and would have strengthened the allocation process [33]. A true randomisation process aims to prevent baseline confounding factors between study groups, ensuring they are well balanced and strengthening the study [34]. Despite the process ambiguity, there were no significant differences $(P>0.05)$ between the group demographics, increasing trial robustness.

A major flaw was the lack of blinding. Given the study's nature, participant and radiographic-assessor blinding were not possible. However, blinding could have been employed for data collection at clinical assessment, shoulder function score (SFS) recording and at data and statistical analyses. This would have reduced the impact of observer or detection biases [35].

The description of data collection methods were variable; however, a thorough description of the assessment technique for the primary outcome time-to-union is provided. This is a difficult end-point to assess, but a clear definition is denoted, with a standardised, reproducible technique described. The study uses 4-weekly radiographs, and although pragmatic and reproducible (enhancing external validity), this method only allows calculation of the time-to-union to the nearest 4-week interval, bringing detrimental imprecision to the study.

Other outcomes are measured more reliably, using contralateral comparison on standardised radiographs for shortening and computer tomography (CT) measurements for non-/mal-union. This is commendable as CT is the gold-standard assessment for union discrepancies, and the shortening measurement method is a standardised technique shown to have high agreement with CT measurements and high repeatability $[8,36]$. This makes the study reproducible, improving its external validity. Similarly, standardised, well-recognised SFSs are utilised [37, 38]. However, description of the data collection method is brief; a negative point. The SFS results were collected via patient questionnaires at 2 years, leading to non-responder and recall bias as well as placing heavy reliance on selfreporting, which often results in a high loss to follow-up [34, 39, 40]. However, no mention of this was detailed, with participants apparently accounted for throughout which, if true, is commendable in reducing the attrition bias effect [34]. However, this is difficult to achieve, thus failure to mention it leads to suspicion.

Details of patients lost to follow-up, excluded from or declining to participate in the trial are not provided. Inclusion of a CONSORT-type flow diagram [41] defining enrolment, allocation and follow-up numbers would resolve this and significantly strengthen the study. The authors disclose cross-over between treatment groups resulting in contamination bias [42]. However, only perprotocol analysis is conducted with no intention-to-treat analysis, which would have reduced the impact on the randomisation process and avoided selection bias [35]. This significantly weakens the study as intention-to-treat analysis would have provided the most conservative estimate of relative effect size, thus demonstrating the most reliable significant difference if found, despite the crossover. Comparison of both analyses should have been performed as per-protocol analysis alone may distort the evidence [43].

Another study weakness was discrepancies in the group's follow-up, with the non-operative group unable to begin mobilising until 3 weeks post-injury compared with immediate post-operative mobilisation in the IMN group. Although difficult to assess, this may have introduced performance bias [34], affecting shoulder stiffness or healing rates. However, the outcome methods for the groups were the same.

The lack of a sample-size calculation is a significant weakness, as achieving a statistically calculated sample size increases study strength due to increased power and probability that a significant difference will be discovered [44]. Instead, the overall sample size is small with the study underpowered, more prone to Type II error, and hence less likely to find a significant difference [45]. Conducting the trial over multiple centres would have improved this, as well as increasing external validity.

The study concludes that in patients with MTCF, when compared with non-operative management, IMN leads to significantly $(P<0.05)$ better shoulder function at 2 years follow-up, as well as faster time-to-union, lower non- and 
delayed union rates and less clavicular shortening. However, it found no significant difference in the total number of complications between groups.

\section{Paper 2}

This single-centre RCT assessed IMN with non-operative treatment in adult patients aged $17-40$ with isolated MTCF. The study aimed to compare the efficacy of an intervention with a comparison treatment, hence a RCT is the preferred study design [32], with the topic remaining relevant.

The paper fails to identify a clear research question at the outset, making trial specifics difficult to ascertain. When assessing PICO methodology [23] the population is clearly defined using detailed eligibility criteria, demonstrating strong study design. However, criterion justification is lacking, e.g. ages 17-40. This is especially relevant given that MTCFs have a bimodal age distribution, occurring in the young adult and ages 55-75 [46, 47]: with the latter therefore excluded. This introduces sample bias and substantially reduces the study's generalisability and external validity as extrapolation to the older subgroup cannot be reliably performed. The authors' affiliated institution is an Army Medical Centre. Therefore, the reason for this age criterion is likely due to a subgroup military population, a point not discussed but further evidenced by the demographic male majority and patient motivation to return to "duty". If true, this should have been openly stated as this subgroup does not reflect the general population, further reducing external validity and generalisability.

The intervention and comparison techniques are well described, strengthening the study and enhancing reproducibility. Limited details regarding the operating surgeons are provided, however, which could mask inter-surgeon variability and proficiency bias [31]. There are discrepancies between the time-to-theatre, (0-2 weeks), thus the amount of bone-healing underway at the time of surgery is variable which could affect results. Importantly this leads to a degree of cross-over and contamination bias [42], as a third of participants in the operative group underwent up to 2 weeks non-operative management before surgery. This could be long enough for significant fracture callus formation $[48,49]$, potentially predisposing union discrepancies. However, no consideration is given to this merging of the intervention and comparison techniques, reducing the likelihood of significant differences being found. Thus, results must be interpreted conservatively.

The outcomes are not clearly stated. Only on reaching the discussion section is "the goal" of the study detailed, implying the outcomes are SFS and non-union rate. Standardised, validated SFSs are used which is a positive due to their reliability, availability and validity $[50,51]$, as well as ensuring the study's reproducibility and generalisability. However, because they are patient-reported questionnaires they do carry the aforementioned negatives of non-responder and recall bias.

The randomisation process description is inadequate. There is no detail regarding how the initial randomisation was generated or who was conducting the randomisation and allocation processes. Hence this remains a questionable method of true randomisation with a lack of independent audit trail, leaving it open to potential tampering [33]. Analysing group demographic data for significant differences can assess whether the randomisation process has overcome confounding factors: something this paper did not perform, another negative point.

The same blinding issues are true here as in paper 1, weakening the study by exposing it to detection bias [35], with the aforementioned improvements to study design relevant.

The methods of data collection are relatively well described, with SFS questionnaires completed at initiation and at regular intervals up to 1 year post-injury, allowing progress monitoring. However, secondary outcome assessment methods for union and shortening were less reliable. Positives were standardised X-rays for each participant, reducing inter-participant variability regarding discrepancies in rotation or magnification on X-rays, and separate examiners performing radiographic measurements and averaging their individual findings for an overall result with increased accuracy. However, standard rulers and goniometers were used, both of which are open to instrument and assessor bias [52]. Also, the definition given for "healing" (union final outcome point) was ambiguous, defined as "callus across the fracture site", with no criteria provided. This lack of precision will lead to assessor inter-variability, contributing to decreased accuracy, as well as making the overall study less reproducible, reducing its generalisability.

The study lacks a CONSORT-type flow diagram [41] and provides little information regarding the numbers of participants involved. It is stated that 57 enrolled, but no details are given concerning the overall number approached, participants changing treatment group from their random allocation, or any being lost to follow-up. If true, then both the latter strengthen the study considerably, but should not be assumed.

A positive point was the use of identical follow-up for both groups. This reduces treatment method confounding factors, and allows assessment of their pure effect more accurately. However, few details regarding post-treatment rehabilitation are provided, decreasing reproducibility and external validity. If rehabilitation involved intense, regular physiotherapy sessions, this may not be generalisable to most healthcare systems where multiple factors make this unfeasible. 
There is no power calculation and the sample size is small, the negatives of which have been discussed previously. In the text, limited result information is provided and not easily extrapolated, e.g. SFS showed a significant difference $(P<0.04)$ at 3 weeks, but analysis to 1 -year follow-up was not provided. Thus, the study temporally limits itself, and does not denote whether this difference is maintained long-term: information that is essential when considering the techniques for use in the general population, which is a major weakness.

The study concludes that in young adults with MTCF, when compared with non-operative management, IMN gives superior SFS at 3 weeks, no significant difference in union rates, but a higher overall complication rate.

\section{Paper 3}

This single-centre RCT compared elastic IMN with nonoperative treatment of displaced MTCF in patients aged 18-65. As previously discussed, a RCT remains the preferred study design [32]. Although the paper confirmed its aim, there was no fully PICO-adherent research question [23]. Thorough eligibility criteria are provided, accurately defining the study population, though criteria justification was lacking. Age was again limited, with the aforementioned disadvantages remaining relevant. Treatment methods were described in detail, following standardised techniques allowing reproducibility, enhancing external validity. However, there was again a lack of detail regarding the surgeons operating. Outcome measurements were clearly identified and detailed, strengthening the study, enhancing readability and reproducibility. However, none were designated a priori, a limitation identified by the authors, suggesting they deduced the outcomes retrospectively.

The randomisation process was well described, using an accepted standardised balanced 4-block randomisation method. The paper excels where the others failed in providing specifics regarding the allocation process, detailing how the randomisation sequence was generated, allocated and by whom, enhancing study strength. However, the staff generating and allocating the randomisation sequence were the surgeons involved in the study, introducing bias and demonstrating a lack of blinding, a theme continued throughout the paper. This lack of an independent, external party and a defined audit trail reduces the process validity, leaving it exposed to tampering, resulting in a less robust trial design. The fixed-block randomisation method was somewhat predictable, especially as the block-size was known to the surgeons, and a variable-block randomisation would have been superior [33]. The assigned treatment options of patients lost to follow-up were re-used in an attempt to maintain the original randomisation, but via a questionable method. Generating larger numbers of randomisation options initially with the allowance for drop-outs would have been more valid [33]. Despite these limitations, no significant differences were found between the group demographics, a positive point in removing confounding factors and allowing a fairer comparison [34].

The SFS outcomes used were the DASH and Constant scores which are validated, well-recognised, responsive, readily-available, reproducible scores $[37,38]$. The DASH questionnaires were assessed weekly for the first 6 months, allowing close observation of participant progression. However, due to expense and practicality, patients were seen monthly thereafter where four questionnaires were collected. This pragmatic approach introduces the risk that patients may complete all forms together retrospectively, an identified compliance limitation. The Constant score is used for the SFS at 6 and 24 months, though no justification is given for its replacement of the DASH score at this stage, which is especially relevant as the DASH scores demonstrated significant differences up to, but not after 18 weeks, whereas the Constant score showed significant differences at 6 and 24 months. Use of both scores throughout the follow-up would have increased the reliability and validity of the result, but would be less pragmatic, and may lead to increased loss to follow-up along with the aforementioned bias issues associated with questionnaire use [34, 39, 40].

The radiological evaluation methods were well described, strengthening the study. Regular, standardised X-rays were used to reduce inter-patient variability and increase the chance of pinpointing the moment of union. However, no assessor details were provided and definitions of endpoints were vague and non-reproducible, reducing external validity. Use of CT was employed if there was no obvious union after 24 weeks, which is a previously mentioned positive. However, surgery was then offered to those with a confirmed non-union. Given that follow-up lasted 2 years, this may have led to contamination bias and cross-over. Ten patients developed non-union, but no details regarding further surgery performed are provided. If significant crossover did occur, this will bias results and appropriate intention-to-treat and per-protocol analyses for outcomes after that period should be performed and compared as discussed previously.

This paper provides good detail regarding patient numbers, including patients excluded, those declining to participate and those lost to follow-up. However, no sample-size calculation was performed and the study is underpowered, increasing the likelihood of false-negative results as previously discussed [44, 45].

The paper concludes that in adults with MTCF, when compared with non-operative management, IMN demonstrated significantly $(P<0.05)$ better SFS, less shortening, fewer complications and shorter time-to-union. 
Table 7 Summary table of the reviewed papers based on PICO methodology [23]

\begin{tabular}{|c|c|c|c|c|}
\hline Study & Population & Intervention & Comparison & Stated outcome/findings \\
\hline $\begin{array}{l}\text { Paper 1: } \\
\text { Smekal et al. } \\
{[19]}\end{array}$ & $\begin{array}{l}112 \text { participants } \\
\text { (age 18-65) }\end{array}$ & $\begin{array}{l}\text { Elastic stable } \\
\text { intramedullary nailing } \\
(n=60)\end{array}$ & $\begin{array}{l}\text { Non-operative } \\
\text { management (sling) } \\
(n=52)\end{array}$ & $\begin{array}{l}\text { IMN demonstrated significantly }(P<0.05) \\
\text { better shoulder function at } 2 \text { years follow-up, } \\
\text { faster time-to-union, lower non- and delayed } \\
\text { union rates and less clavicular shortening } \\
\text { No significant difference in the total number of } \\
\text { complications between groups }\end{array}$ \\
\hline $\begin{array}{l}\text { Paper 2: Judd } \\
\text { et al. [65] }\end{array}$ & $\begin{array}{l}57 \text { participants } \\
\text { (aged } 17-40)\end{array}$ & $\begin{array}{l}\text { Intramedullary nailing } \\
\text { (Hagi pin) }(n=29)\end{array}$ & $\begin{array}{l}\text { Non-operative } \\
\text { management (sling) } \\
(n=28)\end{array}$ & $\begin{array}{l}\text { IMN demonstrated significantly }(P<0.04) \\
\text { superior SFS at } 3 \text { weeks } \\
\text { Higher overall complication rate (though } \\
\text { significance testing not performed) } \\
\text { No significant difference in union rates }\end{array}$ \\
\hline $\begin{array}{l}\text { Paper 3: } \\
\text { Smekal et al. } \\
\text { [66] }\end{array}$ & $\begin{array}{r}60 \text { participants } \\
\text { (aged 18-65) }\end{array}$ & $\begin{array}{l}\text { Elastic stable } \\
\text { intramedullary nailing } \\
(n=30)\end{array}$ & $\begin{array}{l}\text { Non-operative } \\
\text { management (sling) } \\
(n=30)\end{array}$ & $\begin{array}{l}\text { IMN demonstrated significantly }(P<0.05) \\
\text { better SFS, less shortening, fewer } \\
\text { complications and shorter time-to-union }\end{array}$ \\
\hline
\end{tabular}

\section{Discussion}

MTCFs are common and traditionally treated non-operatively [9-11]. Although this can be successful, recent studies have shown it can lead to serious cosmetic and functional complications $[1,3,12,13]$. IMN presents a biomechanically sound alternative and potentially avoids many of the aforementioned complications, boasting superior functional results earlier and a faster return to normal activities [19]. However, some studies have shown higher complication rates $[17,20]$. This review appraised the contemporary evidence, with results comparing IMN with non-operative management in adult MTCF to ascertain which is more beneficial for shoulder function (primary objective) and regarding complication rates (secondary objective); summarised in Table 7:

With regards to shoulder function, all three papers demonstrated an association between IMN and a significantly $(P<0.05)$ superior SFS. However, all are flawed. Paper 1 only provides functional scores at 2 years, and cannot provide information regarding early post-operative weeks, thus it cannot assess early return to daily activities. Conversely, paper 2 calculated significance scores up to 3 weeks. Paper 3 showed an initial significant difference, but this declined until no longer significant at 18 weeks onwards, after which the SFS used was switched, then showing a significant long-term difference. All 3 papers had multiple limitations, therefore overall findings must be considered conservatively and further research in the form of well-designed RCTs is required. On balance, however, results appear to show IMN as producing a better functional outcome than non-operative management.

When considering the secondary objective of complications, the results are less conclusive, (findings shown in Table 7). Although paper 1 has a higher power, it displayed numerous flaws, especially compared with paper 3 , which demonstrated stronger study design. The underpowered nature of papers 2 and 3 mean they cannot be considered singularly conclusive, highlighting the fact that further research is required, with complications individually identified in order to truly assess them in the interests of patient safety [53].

When considering the implications for future clinical practice, the overall external validity is salient. Clavicle fractures have a bimodal age distribution [46, 47], but all papers limited the trial population age, excluding most or all of the older group, reducing generalisability, as findings cannot be universally extrapolated. Nevertheless, the remaining aspects of the trials are reproducible, with detailed techniques and assessment methods provided and widely available implants used, adding to study external validity, making it feasible to implement into practice. However, the effect of the aforementioned limitations must be considered before proceeding.

A salient factor to practice is cost, which none of the papers discussed. Initial surgical costs are higher than nonoperative treatment, hence operative treatment of all MTCFs would substantially increase management costs, although if it resulted in a faster return to work then the financial benefits gained could justify this. The costeffectiveness of operating also depends on the longevity of the functional advantage gained [54], therefore highlighting the need for further research evaluating the cost-benefit analysis of treatment methods, especially given the current need for greater accountability in healthcare spending.

Certain fracture-patterns of MTCFs may show an increased benefit compared to others when comparing the two treatment methods, which papers 1 and 3 alluded to by sub-dividing the MTCFs into simple, wedge and comminuted/complex fractures. This showed IMN had the most 
significant improvement in functional scores in comminuted fractures, despite the higher incidence of shortening, due to stabilisation allowing a faster rehabilitation, and hence a better long-term outcome. This highlights another area for further research to identify how fracture subgroups progress with IMN, hence identifying those that could be still managed non-operatively, reducing costs and thus making enrolment into practice more achievable.

In papers 1-3 a randomisation method has been used for treatment allocation. Although this is appropriate in a trial setting, for clinical practice a more considered approach must be implemented based on the best evidence available. Each patient must be assessed individually for their suitability to each management option before coming to a decision with the patient, rather than a blanket approach being adopted. As well as the abovementioned factors of age and fracture configuration, patient factors such as comorbidities, expectations, occupation and activity level will have an influence on the treatment type selected and must be considered when determining the treatment option.

Evidence-based medicine involves appraisal, evaluation and judicious use of the current best evidence to make appropriate decisions about the care of individual patients [23]. When considering the initial research question, all the papers demonstrated a significant $(P<0.05)$ advantage of IMN over non-operative management in displaced MTCF with regards to shoulder function, but no consensus with regards to complication rates. All conclusions drawn need to be viewed conservatively due to the aforementioned limitations, in particular the age restrictions. Further, highquality research addressing the aforementioned issues, ideally in the form of well-designed, multi-centre RCTs is required to allow acceptable implementation of IMN of MTCF into widespread practice. However, early results demonstrate that in young patients with displaced MTCF, who are motivated to return to work, IMN provides superior functional results and should be considered. However, the importance of considering each patient individually as to their suitability for each management option, before coming to an informed decision with the patient rather than having a blanket approach to MTCF is essential.

Conflict of interest No conflicts of interest or sources of funding to declare.

Open Access This article is distributed under the terms of the Creative Commons Attribution License which permits any use, distribution, and reproduction in any medium, provided the original author(s) and the source are credited.

\section{Appendix: Literature search strategies}

All searches performed 20 September, 2012.

\section{EMBASE}

1. Conservative treatment/or nonoperative.mp. 48,623

2. Exp conservative treatment/or non-operative.mp. 355,898

3. 1 or 2 361,883

4. Exp intramedullary nailing/or exp intramedullary nail/or $\quad 20,922$ intramedullary.mp.

5. 3 and 4

6. Exp clavicle fracture/or exp clavicle/or clavicle.mp.

8,871

7. 5 and 6

8. Limit 7 to English language

9. Limit 8 to human

10. Limit 9 to last 10 years

11. Limit 10 to clinical trial

Web of knowledge

1. Intramedullary/AND clavicle/AND fracture 168

2. Limit 1 to English language

105

3. Limit to clinical trial 7

\section{References}

1. Houwert RM, Wijdicks FJ, Steins Bisschop C, Verleisdonk EJ, Kruyt M (2012) Plate fixation versus intramedullary fixation for displaced mid-shaft clavicle fractures: a systematic review. Int Orthop 36(3):579-585

2. Robinson CM (1998) Fractures of the clavicle in the adult. Epidemiology and classification. J Bone Jt Surg (Br Vol) 80(3):476484

3. Craig EV (1996) Fractures of the clavicle. In: Rockwood CAJ, Green DP (eds) Rockwood and Green's fractures in adults, 5th edn. Lippincott-Raven, Philadelphia, pp 1109-1161

4. Nordqvist A, Petersson C (1994) The incidence of fractures of the clavicle. Clin Orthop Relat Res 300:127-132

5. Allman FL (1967) Fractures and ligamentous injuries of the clavicle and its articulation. Journal of Bone \& Joint Surgery. 49(4):774-784

6. Postacchini F, Gumina S, De Santis P, Albo F (2002) Epidemiology of clavicle fractures. J Shoulder Elbow Surg 11(5): 452-456

7. Neviaser JS (1980) Injuries of the clavicle and its articulations. Orthopaedic Clinics of North America. 11(2):233-237

8. Lazarides S, Zafiropoulos G (2006) Conservative treatment of fractures at the middle third of the clavicle: the relevance of shortening and clinical outcome. J Shoulder Elbow Surg 15(2):191-194

9. Rowe CR (1968) An atlas of anatomy and treatment of midclavicular fractures. Clin Orthop Relat Res 58:29-42

10. Neer CS (1960) Nonunion of the clavicle. The Journal of the American Medical Association. 172:1006-1011

11. Kim W, McKee MD (2008) Management of acute clavicle fractures. Orthopaed Clin N Am 39(4):491-505 (vii)

12. Hill JM, McGuire MH, Crosby LA (1997) Closed treatment of displaced middle-third fractures of the clavicle gives poor results. Journal of Bone \& Joint Surgery. 79(4):537-539 
13. Postacchini R, Gumina S, Farsetti P, Postacchini F (2010) Longterm results of conservative management of midshaft clavicle fracture. Int Orthop 34(5):731-736

14. Denard PJ, Koval KJ, Cantu RV, Weinstein JN (2005) Management of midshaft clavicle fractures in adults. American Journal of Orthopaedics (Belle Mead NJ). 34(11):527-536

15. Lenza M, Belloti JC, Dos Santos JBG, Matsumoto MH, Faloppa F (2009) Surgical interventions for treating acute fractures or non-union of the middle third of the clavicle. Cochrane Database Systematic Review 4:CD007428

16. Böstman O, Manninen M, Pihlajamäki H (1997) Complications of plate fixation in fresh displaced midclavicular fractures. The Journal of Trauma: Injury, Infection, and Critical Care. 43(5): 778-783

17. Frigg A, Rillmann P, Perren T, Gerber M, Ryf C (2009) Intramedullary nailing of clavicular midshaft fractures with the titanium elastic nail: problems and complications. The American Journal of Sports Medicine. 37(2):352-359

18. Omanik S (1952) Intramedullary nailing of fractures of the clavicle. Lek List. 7(17):420-424

19. Smekal V, Irenberger A, Attal RE, Oberladstaetter J, Krappinger D, Kralinger F (2011) Elastic stable intramedullary nailing is best for mid-shaft clavicular fractures without comminution: results in 60 patients. Injury. 42(4):324-329

20. Grassi FA, Tajana MS, D'Angelo F (2001) Management of midclavicular fractures: comparison between nonoperative treatment and open intramedullary fixation in 80 patients. The Journal of Trauma: Injury, Infection, and Critical Care. 50(6): 1096-1100

21. Lenza M, Belloti JC, Andriolo RB, Dos Santos JBG, Faloppa F (2009) Conservative interventions for treating middle third clavicle fractures in adolescents and adults. Cochrane Database Systematic Review 2:CD007121

22. Hill A \& Spittlehouse C Evidence based medicine - what is critical appraisal? Heyward Medical Communications, Newmarket, 2003. Online PDF: Available from: http://www.medicine.ox. ac.uk/bandolier/painres/downlaod/whatis/What_is_critical_appraisal. pdf

23. Sackett DL, Rosenberg WM, Gray JA, Haynes RB, Richardson WS (1996) Evidence based medicine: what it is and what it isnt. Br Med J 312(7023):71-72

24. Oxman AD, Sackett DL, Guyatt GH (1993) Users'guides to the medical literature. I. How to get started. The Evidence-Based Medicine Working Group. J Am Med Assoc 270(17):2093-2095

25. Anderson LW, Krathwohl D (2001) A taxonomy for learning, teaching and assessing: a revision of Blooms taxonomy of educational objectives. Longman, New York

26. Sood A, Ghosh AK (2006) Literature search using PubMed: an essential tool for practising evidence-based medicine. The Journal of the Associations of the Physicians of India. 54:303-308

27. Dawes M, Davies P, Gray A, Mant J, Seers K (2005) Evidencebased practice: a primer for health care professionals. Churchill Livingstone, Elsevier

28. Motschall E, Falck-Ytter Y (2005) Searching the MEDLINE literature database through PubMed: a short Guide. Onkologie 28(10):517-522

29. Doig GS, Simpson F (2003) Efficient literature searching: a core skill for the practice of evidence-based medicine. Intensive Care Med 29(12):2119-2127

30. Critical Appraisal Skills Programme (CASP) (2006). 10 questions to help you make sense of qualitative research. In: Public Health Resource Unit, Oxford, 2006, 1-4. Available from: www.phru. nhs.uk/Doc_Links/Qualitative_Appraisal_Tool.pdf

31. Hartman JM, Forsen JW, Wallace MS, Neely JG (2002) Tutorials in clinical research: part IV: recognizing and controlling bias. Laryngoscope. 112(1):23-31
32. Greenhalgh T (1997) How to read a paper. Getting your bearings (deciding what the paper is about). Br Med J 315(7102):243-246

33. Kang M, Ragan BG, Park JH (2008) Issues in outcomes research: an overview of randomization techniques for clinical trials. Journal of Athletic Training. 43(2):215-221

34. Ajetunmobi O (2002) Making sense of critical appraisal. Oxford University Press, London, New York

35. Jüni P, Altman DG, Egger M (2001) Systematic reviews in health care: assessing the quality of controlled clinical trials. Br Med J 323(7303):42-46

36. Smekal V, Deml C, Irenberger A et al (2008) Length determination in midshaft clavicle fractures: validation of measurement. J Orthop Trauma 22(7):458-462

37. MacDermid JC, Richards RS, Donner A, Bellamy N, Roth JH (2000) Responsiveness of the short form-36, disability of the arm, shoulder, and hand questionnaire, patient-rated wrist evaluation, and physical impairment measurements in evaluating recovery after a distal radius fracture. Journal of Hand Surgery. 25(2):330-340

38. Constant CR, Murley AH (1987) A clinical method of functional assessment of the shoulder. Clin Orthop Relat Res 214:160-164

39. Johnson B, Turner L (2003) Data collection strategies in mixed methods research. In: Tashakkori A, Teddlie C (eds) Handbook of mixed methods in social and behavioural research. SAGE Publications Inc., United States of America, p 768

40. Armstrong JS, Overton TS (1977) Estimating non-response bias in mail surveys. J Mark Res 14:396-402

41. Schulz KF, Altman DG, Moher D \& Group C (2010) CONSORT 2010 statement: updated guidelines for reporting parallel group randomised trials. Br Med J 340:332

42. Godwin M, Ruhland L, Casson I et al (2003) Pragmatic controlled clinical trials in primary care: the struggle between external and internal validity. BMC Med Res Methodol 3:28

43. The Cochrane Collaboration (2002) Further issues in meta-analysis: Intention to treat issuesOnline PDF: Available from: http:// www.cochrane-net.org/openlearning/HTML/mod14-4.htm

44. Kimani P (2011) What do the results mean? "Statistical thinking". Understanding research and critical appraisal MSc module course material: The University of Warwick

45. Petrie A (2006) Statistics in orthopaedic papers. Journal of Bone \& Joint Surgery (British Volume). 88(9):1121-1136

46. Singh R, Rambani R, Kanakaris N, Giannoudis PV (2012) A 2-year experience, management and outcome of 200 clavicle fractures. Injury. 43(2):159-163

47. Court-Brown CM, Caesar B (2006) Epidemiology of adult fractures: a review. Injury. 37(8):691-697

48. Frost HM (1989) The biology of fracture healing. An overview for clinicians. Part I. Clin Orthop Relat Res 248:283-293

49. Frost HM (1989) The biology of fracture healing. An overview for clinicians. Part II. Clin Orthop Relat Res 248:294-309

50. Williams GN, Gangel TJ, Arciero RA, Uhorchak JM, Taylor DC (1999) Comparison of the Single Assessment Numeric Evaluation method and two shoulder rating scales. Outcomes measures after shoulder surgery. The American Journal of Sports Medicine. 27(2):214-221

51. L'Insalata JC, Warren RF, Cohen SB, Altchek DW, Peterson MG (1997) A self-administered questionnaire for assessment of symptoms and function of the shoulder. J Bone Joint Surg 79(5):738-748

52. Petherick M, Rheault W, Kimble S, Lechner C, Senear V (1988) Concurrent validity and inter-tester reliability of universal and fluid-based goniometers for active elbow range of motion. Phys Ther 68(6):966-969

53. General Medical Council (GMC) (2006) Guidance for doctors: good medical practice. GMC, London 2006:1-52

54. Pearson AM, Tosteson AN, Koval KJ et al (2010) Is surgery for displaced, midshaft clavicle fractures in adults cost-effective? 
Results based on a multicenter randomized, controlled trial. J Orthop Trauma 24(7):426-433

55. Wijdicks FJ, Van der Meijden OA, Millett PJ, Verleisdonk EJ, Houwert RM (2012) Systematic review of the complications of plate fixation of clavicle fractures. Arch Orthop Trauma Surg 132(5):617-625

56. Assobhi JE (2011) Reconstruction plate versus minimal invasive retrograde titanium elastic nail fixation for displaced midclavicular fractures. Journal of Orthopaedics \& Traumatology. 12(4):185-192

57. Duan X, Zhong G, Cen S, Huang F, Xiang Z (2011) Plating versus intramedullary pin or conservative treatment for midshaft fracture of clavicle: a meta-analysis of randomized controlled trials. J Shoulder Elbow Surg 20(6):1008-1015

58. McKee MD (2010) Clavicle fractures in 2010: sling/swathe or open reduction and internal fixation? Orthopaedic Clinics of North America. 41(2):225-231

59. Wijdicks FJ, Houwert RM, Dijkgraaf MG et al (2011) Rationale and design of the plate or pin (POP) study for dislocated midshaft clavicular fractures: study protocol for a randomised controlled trial. Trials. 12:177

60. Ferran NA, Hodgson P, Vannet N, Williams R, Evans RO (2010) Locked intramedullary fixation vs plating for displaced and shortened mid-shaft clavicle fractures: a randomized clinical trial. J Shoulder Elbow Surg 19(6):783-789

61. Proubasta IR, Itarte JP, Cáceres EP et al (2002) Biomechanical evaluation of fixation of clavicular fractures. J South Orthop Assoc 11(3): 148-152

62. Simon P (2010) Mid-clavicle fractures in adults: surgery or not? Eur J Orthop Surg Traumatol 20(7):521-525

63. O'Brien MJ, Savoie FH III (2010) Clavicular fractures. Current Orthopaedic Practice. 21(5):429-434

64. Thompson DJ (2005) Clavicle fracture and its complications. Trauma. 47(1):35-61

65. Judd DB, Pallis MP, Smith E, Bottoni CR (2009) Acute operative stabilization versus nonoperative management of clavicle fractures. The American Journal of Orthopaedics (Belle Mead NJ). 38(7):341-345

66. Smekal V, Irenberger A, Struve P, Wambacher M, Krappinger D, Kralinger FS (2009) Elastic stable intramedullary nailing versus nonoperative treatment of displaced midshaft clavicular fractures-a randomized, controlled, clinical trial. J Orthop Trauma 23(2):106-112 